\title{
ANIROPOFAGIA ORGANIZACIONAL
}

Thomaz Wood Jr. Mestre e Doutorando em Administração de Empresas na EAESP/FGV, Professor do Departamento de Administração da Produção e de Operações Industriais da EAESP/FGV e Consultor de Empresas. E-mail: twood@eaesp.fgvsp.br

Miguel P. Caldas Mestre e Doutorando em Administração de Empresas na EAESP/FGV, Professor do Departamento de Administração Geral e Recursos Humanos da EAESP/FGV e Consultor de Empresas. E-mail: mcaldas@eaesp.fgvsp.br

RESUMO: A questão da utilização de tecnologia administrativa originária de países desenvolvidos por empresas no Brasil pode ser vista sob duas perspectivas: pela perspectiva das empresas locais, que a adotam pressionadas pelo novo contexto competitivo, e pela perspectiva das empresas que se instalam no País e que trazem essas práticas diretamente de suas matrizes. Em ambos os casos, a importação de modelos estrangeiros mostra-se problemática. O objetivo deste artigo é, primeiro, discutir por que ocorre essa importação, depois, mostrar que peculiaridades locais impedem sua implantação como previsto e, por fim, propor e ilustrar um "método antropofágico" de ação para essa importação em países emergentes.

ABSTRACT: The utilization by organizations in Brazil of managerial technology originated from developed countries can be seen by two perspectives: by the angle of local firms, which adopt foreign administrative models due to pressures of a new competitive context, and by the angle of foreign newcomers, which bring such practices directly from their countries of origin. In both cases, the import of foreign models appears to be troublesome. The objective of this article is, firstly, to discuss why such import occurs; secondly, to show how local characteristics prevent its implementation as planned; and, thirdly, to propose and to illustrate an "anthropophagic method" which can be used when importing foreign managerial technology into emerging countries.

PALAVRAS-CHAVE: antropofagia, países emergentes, importação de tecnologia administrativa, modismos, mudança organizacional.

KEY WORDS: anthropophagy, emerging countries, import of managerial technology, management fads, organizational change. 
"Só a antropofagia nos une.

Socialmente. Economicamente.

Philosophicamente. (...)

Tupy or not tupy, that is the question."

Oswald de Andrade (1928)

\section{LIÇÕES DE UM PASSADO DISTANTE}

À época do descobrimento, o Brasil era habitado por cerca de 1 milhão de americanos nativos, aproximadamente a mesma população do país dos descobridores. Os americanos nativos foram, em sua maioria, dóceis e servis ao colonizador, o que, somado à plasticidade dos portugueses, criou um verdadeiro caldeirão étnico que deu origem ao povo brasileiro.

Entre os americanos nativos, porém, existiam tribos que praticavam a antropofagia, um ritual de guerra em que os vencedores se alimentavam dos vencidos. Ao devorar o vencido, o vencedor acreditava estar sugando a sua coragem e energia, num ato de respeito e honra. Portanto, era preciso que o vencido fosse um guerreiro corajoso, à altura do seu contendor. Sabe-se que muitos jesuítas foram salvos de serem devorados pelos índios justamente por sua covardia. Quando os jesuítas aprisionados mostravam um comportamento menos que digno, chorando e implorando piedade, seus algozes sentiam engodos só de pensar em alimentarse de carne de tão pouca qualidade.

A antropofagia foi retomada, como metáfora, no Brasil do século XX, por uma vanguarda cultural urbana. Essa vanguarda denunciava o que entendia ser uma apropriação exagerada e sem sentido da cultura estrangeira. Ao mesmo tempo, esses intelectuais estavam comprometidos com a modernidade e o cosmopolitismo de sua época. O que propunham, um "antropofagismo literário", significava a apropriação sem pudores de idéias e conceitos estrangeiros, mas defendia que eles fossem temperados por novos significados e alterados pelas cores e

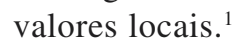

À medida que o Brasil, como outros países emergentes, insere-se em uma nova ordem econômica, marcada pela hipercompetitividade e pela hiperconectividade, crescem as pressões para a adoção de práticas gerenciais mais avançadas, que capacitem as empresas locais a competir em um cenário globalizado. A adoção pura e simples de modelos alienígenas pode, porém, ser frustrante e desastrosa. Por isso, acreditamos que seja o momento para retomar o antigo ritual antropofágico dos americanos nativos e levar para o caldeirão as centenas de Druckers, Porters, Senges, Hammers e Prahalads que inundam as prateleiras e as mentes de consultores e executivos (ver Figura 1). Os que provarem sua coragem, valor e adequação ao contexto dos países emergentes poderão ser utilizados.

Figura 1 - Executivos brasileiros põem à prova as idéias do Sr. Porter

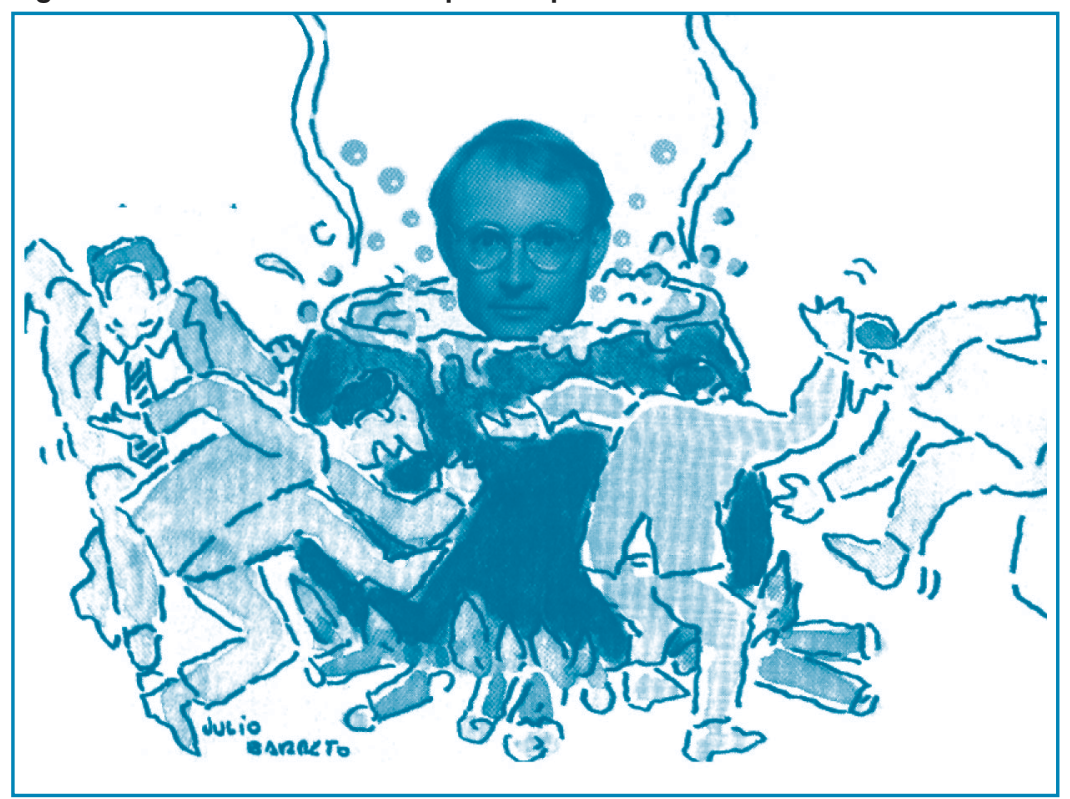

Fonte: BARRETO, Julio. In: WOOD JR., Thomaz. Um dia no circo. CartaCapital, ano II, n.50, p.82-83, jun. 1997.

Os objetivos deste trabalho são os seguintes: (a) discutir as peculiaridades institucionais e organizacionais do ambiente brasileiro de negócios; (b) mostrar por que tais particularidades provocam resultados inesperados na importação de tecnologia gerencial estrangeira; e (c) propor e ilustrar um método de ação (que denominamos "método antropofágico") para a adaptação criativa e apropriada de tecnologia gerencial importada por empresas em países emergentes.

O restante do texto está estruturado da seguinte forma: a segunda seção trata das peculiaridades dos países emergentes, com ênfase no caso brasileiro; a terceira seção trata da questão da importação de tecnologia gerencial; a quarta seção discute as razões que motivam a procura por essa impor-
1. ANDRADE, 0. Manifesto Antropófago, Revista de Antropofagia, v.1, n.1, 1928, p.3-7. 
tação no Brasil; a quinta seção mostra como empresas locais reagem à importação de tecnologia gerencial; a sexta seção discute o método proposto para a apropriação criativa de tecnologias gerenciais importadas, a "antropofagia organizacional"; e a última seção apresenta comentários finais sobre o tema.

\section{EMBORA OS PAÍSES EMERGENTES} APRESENTEM GRANDE

\section{ATRATIVIDADE, UM COMEÇO PROMISSOR PODE RESULTAR EM DESASTRE E FRUSTRAÇÃO.}

\section{PAÍSES EMERGENTES: OPORTUNIDADES E DESAFIOS}

Nos últimos anos, tem sido crescente o volume de investimentos de corporações de países desenvolvidos na América Latina. A perspectiva de continuidade do movimento no futuro é forte, uma vez que as condições políticas e econômicas da região se estabilizam.

Dois fatores estão por trás desse fenômeno: primeiro, as condições empresariais desfavoráveis nos países desenvolvidos, nos quais a maturidade dos mercados, o acirramento da concorrência, o custo da mão-de-obra, bem como as pressões do movimento ambientalista, inibem investimentos; segundo, as condições empresariais aparentemente favoráveis nos países em desenvolvimento, nos quais a emergência de uma classe média com capacidade de consumo, o custo ainda baixo da mãode-obra e a estabilização econômica e política atraem investimentos.

No Brasil, em particular, o fluxo de investimentos produtivos tem aumentado desde a flexibilização das regras de investimento e de importação no início dos anos 90 . As organizações já em operação estão sendo obrigadas a rever sua conduta empresarial e seus modelos de gestão. Já as organizações que estão sendo instaladas na região precisam adequar seu estilo gerencial e suas práticas administrativas às peculiaridades locais. No entanto, fazer negócios no Brasil, como em outros países emergentes, tem suas par- ticularidades. Instituições ainda pouco consolidadas, instabilidade econômica e cultura organizacional peculiar são elementos que podem fazer estrangeiros mal-avisados sentirem-se como astronautas perdidos em galáxias distantes, obrigados a desvendar profundos mistérios para sobreviver. Tanto nesse caso quanto naquele de empresas nacionais que começam a adotar práticas gerenciais "globais", é importante fazer uma revisão crítica da teoria e da prática administrativas importadas de países desenvolvidos.

\section{EMPREENDEDORISMO EM PAÍSES EMERGENTES: CIÊNCIA E ARTE}

Em muitos círculos de negócios, parece haver consenso que fazer negócios além das fronteiras dos países desenvolvidos, seja para estrangeiros ou para locais, é uma tarefa de grande complexidade. Uma série de artigos publicados recentemente por The Economist busca registrar as aventuras e desventuras de grandes corporações atraídas pela possibilidade (nem sempre concretizada) de fazer bons negócios em países emergentes. Esses e outros relatos mostram que, embora os países emergentes apresentem grande atratividade, um começo promissor pode resultar em desastre e frustração, e o sonho de grandes taxas de retorno pode acabar em pesadelo. Acostumadas a operar em mercados com alto grau de institucionalização, com regras claras e estáveis, muitas dessas empresas têm dificuldade em assimilar as peculiaridades locais. Acabam sendo vitimadas por tempestades políticas, situações de guerra, corrupção, leis frágeis e instáveis e práticas empresariais e estilos gerenciais (aos seus olhos) exóticos.

Em muitos casos, falta ao estrangeiro entender que os pressupostos que normalmente fundamentam suas práticas podem não ser válidos nos países emergentes. Muitas corporações acabam adotando a chamada "postura etnocêntrica", acreditando que a forma como trabalham em seus países de origem é superior à forma como se trabalha em outros países. Assim, acabam ignorando as diferenças socioculturais. Esse fenômeno, porém, não é restrito às empresas estrangeiras. Muitas empresas locais, premidas pela necessidade de melhorar seus processos de gestão, estão ado- 
tando (irrefletidamente) metodologias importadas. Configura-se, portanto, uma condição de etnocentrismo às avessas. Em ambas as situações, tanto a do estrangeiro quanto a do "estrangeirado", os resultados podem ser danosos para a prática empresarial.

Três casos publicados pela The Economist ilustram as dificuldades do estrangeiro tentando fazer negócios em terras distantes. Um quarto caso mostra uma aliança bem sedimentada entre estrangeiros e locais.

\section{Decepções do estrangeiro em países emergentes}

O primeiro caso é o da Acer, fabricante de microcomputadores de Taiwan, que montou uma fábrica na calma Finlândia para atender ao emergente mercado russo. Com isso, essa empresa evitou a um só tempo a gigantesca e confusa burocracia russa e os riscos de estabelecer uma atividade industrial em um país ainda convulsionado por mudanças políticas e econômicas. A estratégia da Acer mostrou-se superior à da IBM, que instalou, e mais tarde decidiu fechar, uma fábrica na Rússia. Contudo, não conseguiu evitar que 50 caminhões de transporte fossem seqüestrados e que dois motoristas fossem assassinados nos últimos três anos. No plano da concorrência, a Acer enfrenta os fabricantes locais, que conseguem tirar vantagem do seu conhecimento das peculiaridades de se fazer negócios no país. ${ }^{2}$

Em um segundo caso, a megacorporação japonesa Matsushita, de produtos eletrônicos, criou, de 1992 a 1996, 30 empresas na China, 27 delas em parceria com empresas locais. Os parceiros acabaram constituindo um problema particular para a empresa. Pouco familiarizados com práticas gerenciais, eles têm a expectativa de receber dividendos da joint venture com base nas previsões iniciais, mesmo que a situação tenha mudado e a empresa esteja trabalhando com prejuízos. Nesse período de implantação, a empresa enfrentou todo tipo de dificuldades: aumento imprevisto de impostos, inflação, elevação dos juros, dificuldades em estabelecer uma estratégia de distribuição coerente, redução da jornada de trabalho etc. Resultado: os investimentos realizados (cerca de 540 milhões de dólares) ainda não foram recu- perados. Ainda otimistas, os dirigentes estão mudando sua expectativa de retorno sobre o investimento de sete para dez anos. ${ }^{3}$

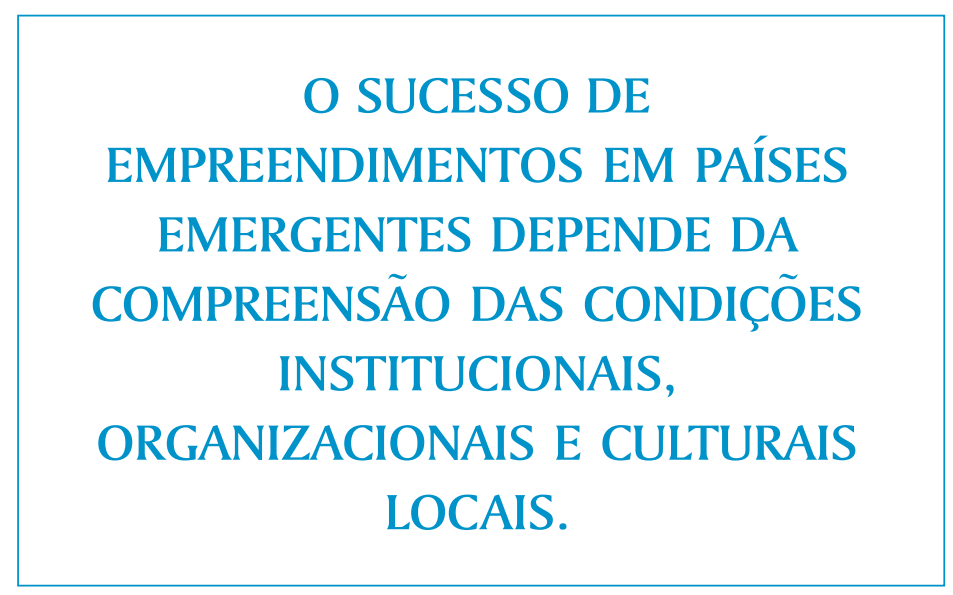

O terceiro caso refere-se à experiência do McDonald's na África do Sul. Com uma das marcas mais conhecidas do mundo, a estratégia de crescimento da rede americana tem favorecido investimentos fora dos Estados Unidos. Na África do Sul, o primeiro problema foi uma disputa pela marca nos tribunais (empresas locais haviam registrado a marca enquanto o McDonald's mantinha-se afastado do país, na era do regime de segregação racial). Vencida a batalha judicial, foi a vez de enfrentar a concorrência local, sólida, bem gerida e mais próxima dos costumes locais. Um dos motivos de orgulho da empresa é sua capacidade de adaptar seus produtos ao gosto local, em cada país em que atua. Mas não foi o que aconteceu na África do Sul. Sem conhecer os hábitos locais, a rede apostou em pequenas alterações em seu cardápiopadrão, confiando no poder da marca. Resultado: participação ainda marginal no mercado e dificuldade de crescer. ${ }^{4}$

\section{Fiat no Brasil: sucesso na contramão da história?}

A indústria automobilística é uma das mais dinâmicas e competitivas do mundo. Globalizada desde praticamente sua origem, ela tem experimentado formas mais avançadas de conectividade desde o final dos anos 80. Foi quando surgiu o conceito de carro mundial, projetado nos centros de tecnologia mais avançados e fabricado em vá-
2. Management brief: Laptops from Lapland. The Economist, Sep. 6th, 1997, p.67-8.

3. Management brief: Matsushita's Chinese burn. The Economist, Sep. 20th,1997, p.75-6.

4. Management brief: Johannesburgers and fries. The Economist, Sep. 27th, 1997, p.75-6. 
rios pontos do mundo. Nesse sentido, o projeto 178, da Fiat Brasil, que deu origem ao Palio, representa um passo na contramão da história. Concebido por uma equipe multinacional, com engenheiros, designers e operários brasileiros, italianos, argentinos e poloneses, o carro teve aceitação imediata no mercado, chegando, em alguns momentos, a desbancar os modelos da (até então invencível) Volkswagen.

O projeto traz lições de adaptabilidade e respeito às condições locais em todos os aspectos: das características do produto (estilo, dimensões e acessórios) à organização da produção (que aproveita a flexibilidade da mãode-obra relativamente barata do Brasil). Seu primeiro teste no mercado brasileiro mostra a importância do respeito às condições locais. ${ }^{5}$

\section{Lições da diversidade}

O que esses casos de sucessos e fracassos podem ensinar? Em um nível mais superficial, que as empresas de sucesso são fle- xíveis e adaptam-se mais facilmente às condições de negócios dos locais em que atuam. Em um nível mais profundo, que o sucesso de empreendimentos em países emergentes depende da compreensão das condições institucionais, organizacionais e culturais locais. Muitas das instituições que sustentam os negócios em países industrializados são inexistentes ou operam em condições precárias em países emergentes. ${ }^{6}$

Críticos poderiam argumentar que o desenvolvimento das economias emergentes levaria naturalmente à adoção de instituições e políticas industriais similares às dos países desenvolvidos. Isso pode, de fato, ocorrer. No entanto, esse argumento padece de duas imperfeições: primeiro, não é possível saber exatamente em que velocidade essas instituições irão amadurecer; segundo, nada garante que esse amadurecimento irá levar à mesma configuração dos países desenvolvidos.

O Quadro 1 mostra algumas características específicas do ambiente de negócios brasileiro. Essas características estão divididas
5. Management brief: a car is born. The Economist, Sep. 13th, 1997, p.68-9.

6. KHANNA, T., PALEPU, K. Why focused strategies may be wrong for emerging markets. Harvard Business Review, v.75, n.4, 1997, p.41-51.
Quadro 1 - Algumas especificidades do ambiente empresarial brasileiro

\begin{tabular}{|c|c|c|}
\hline INSTITUCIONAIS & CULTURAIS & ORGANIZACIONAIS \\
\hline $\begin{array}{l}\text { - Baixo grau de } \\
\text { institucionalização dos } \\
\text { organismos de controle e } \\
\text { coordenação } \\
\text { - Baixa intensidade de } \\
\text { competição: com a presença } \\
\text { de monopólios e oligopólios e } \\
\text { setores cartelizados } \\
\text { - Regulamentação precária da } \\
\text { atividade empresarial: } \\
\text { excesso de regulamentação } \\
\text { em alguns casos, falta de } \\
\text { regulamentação em outros } \\
\text { Comunicação imperfeita no } \\
\text { mercado } \\
\text { - Relações conflituosas entre } \\
\text { clientes e fornecedores, } \\
\text { dificultando alianças e } \\
\text { parcerias }\end{array}$ & $\begin{array}{l}\text { - Personalismo: o indivíduo } \\
\text { acima da comunidade } \\
\text { - Ambigüidade: nada é o que } \\
\text { parece ser e, quando é, pode } \\
\text { também ser algo mais } \\
\text { - Alta distância do poder: } \\
\text { relações sociais marcadas } \\
\text { pela herança escravocrata } \\
\text { - Plasticidade e } \\
\text { permeabilidade: abertura e } \\
\text { fascinação com o } \\
\text { estrangeiro } \\
\text { - Formalismo e "faz-de- } \\
\text { conta": convivência entre } \\
\text { o "mundo de direito" e o } \\
\text { "mundo de fato", mediada } \\
\text { pela ambigüidade e pelos } \\
\text { comportamentos de } \\
\text { fachada }\end{array}$ & $\begin{array}{l}\text { - Estratégia: pouco focada em } \\
\text { função da pouca tradição no } \\
\text { tratamento da questão e das } \\
\text { condições ambientais instáveis } \\
\text { - Estrutura: presença ainda } \\
\text { importante de estruturas } \\
\text { hierárquicas pesadas e de } \\
\text { formas "primitivas" de } \\
\text { organização do trabalho } \\
\text { - Estilo gerencial: marcado } \\
\text { pelo autoritarismo, alta } \\
\text { distância do poder e } \\
\text { centralização das decisões } \\
\text { - Sistemas de informação: } \\
\text { ainda incipientes, com } \\
\text { retenção da informação no } \\
\text { topo } \\
\text { - Sistemas de apoio: pouco } \\
\text { desenvolvidos }\end{array}$ \\
\hline
\end{tabular}


em três grupos: (a) as especificidades institucionais, que se referem às condições estruturais que norteiam e permeiam a atividade empresarial; (b) as especificidades culturais, que influenciam a condução dos negócios, os modelos de gestão e as práticas administrativas; e (c) as especificidades organizacionais, que podem diferenciar as empresas locais das congêneres em outros países.

Embora haja diferenças significativas entre o Brasil e outros países da América Latina, muitas dessas características são comuns à maioria dos países da região. $\mathrm{O}$ ponto fundamental é que elas podem condicionar o sucesso (ou o fracasso) da implementação de novas tecnologias de gestão. Diferentes características implicam o uso de diferentes tecnologias. Implicam, também, o fracasso potencial de tecnologias desenvolvidas em contextos diferentes.

\section{POR QUE SE USA TECNOLOGIA ADMINISTRATIVA IMPORTADA NO BRASIL?}

Se modelos administrativos criados em países desenvolvidos podem não ser adequados à realidade de países emergentes, então por que nações como o Brasil são tão atraídas por eles? Por que tecnologia gerencial, modismos administrativos, livros de "receitas empresariais" e gurus de negócios são importados em tão larga escala?

Listar fatores contextuais como a globalização, a hipercompetitividade, o incremento de novas tecnologias de computação e de comunicação etc. como sendo os motivos pode ser tentador, mas talvez não seja o suficiente para explicar a permeabilidade de organizações brasileiras à parafernália gerencial estrangeira. Esses fatores explicam por que modelos estrangeiros são hoje mais acessíveis e mais facilmente conhecidos por países emergentes, mas não explicam por que países como o Brasil importam esses modelos tão freneticamente e - muitas vezes - a despeito de sua inadequação à realidade local ou às suas necessidades efetivas. Assim, no caso brasileiro, esses fatores contextuais parecem apenas catalisar tendências que já existiam antes. E essas tendências podem ser mais bem entendidas se analisarmos as organizações brasileiras à luz da formação histórica e cultural local e das relações que os brasileiros têm com o estrangeiro.

\section{A formação histórica e cultural brasileira}

Se é verdade que o Brasil é um país latino que compartilha com o restante do continente diversos traços culturais, também é evidente que sua colonização não-espanhola e sua formação histórica peculiar produziram uma mistura singular de traços culturais que ajudam a explicar, no presente, certos comportamentos sociais.

Antes de focalizar tais traços, é importante ressaltar algumas das características da formação brasileira que a tornam distinta daquela de outros países do Novo Mundo. Muitos pensadores da formação cultural brasileira, de Gilberto Freyre ${ }^{7}$ a Darcy Ribei$\mathrm{ro}^{8}$, mostraram que a do brasileiro foi marcada, desde o início da colonização portuguesa, pela supressão das identidades discrepantes e pela repressão a movimentos separatistas. Assim, o povo brasileiro não emergiu do transplante ou da evolução direta de outras formas de sociabilidade, mas do etnocídio e genocídio das populações escravas trazidas (africanas) ou subjugadas (indígenas) pelo colonizador. Não foi exatamente esse o caminho evolutivo seguido, por exemplo, pela colonização da América espanhola. Por outro lado, a colonização portuguesa também se caracterizou pela exploração das riquezas naturais, e não pelo povoamento das terras descobertas com o intuito de construção de uma nova nação. Ao contrário do colonizador inglês na América do Norte, que trouxe a família para lá se fixar, o português a esqueceu, pois via na ocupação das novas terras uma missão de conquista, adequada somente ao homem solteiro.

$\mathrm{O}$ produto historicamente moldado dessas diferenças é um contexto cultural rico, singular e multifacetado, dificilmente ilustrado por características pontuais. Entretanto, ao menos cinco traços culturais brasileiros podem ser úteis para explicar o comportamento organizacional moderno tratado neste ensaio: personalismo, ambigüidade, distância do poder, plasticidade e formalismo. Alguns deles explicam por que a aplicação direta de modelos administrativos estrangeiros costuma não funcionar; outros explicam por que, mesmo assim, o Brasil é tão ávido importador de tecnologia gerencial estrangeira.
7. FREYRE, G. Casa grande e senzala.13.ed. Rio de Janeiro: J. Olympio, 1966.

8. RIBEIRO, D. O povo brasileiro: a formação e o sentido do Brasil. São Paulo: Schwarcz, 1996. 
Em essência, o personalismo explica a tendência de, no Brasil, a aplicação da lei ser reservada ao cidadão anônimo, isolado e sem relações. Em outras palavras, significa fazer, não de imperativos da sociedade, mas da importância social ou necessidade pessoal do indivíduo, a referência para a ação social. Já a ambigüidade explica por que, no Brasil, quase nada é o que parece ser e, quando é o que parece, pode também ser algo mais. A forma de lidar com essa ambigüidade é disfarçá-la como flexibilidade ou adaptabilidade. $\mathrm{O}$ traço da distância do poder mostra por que o brasileiro tende a julgar-se com direitos especiais, que o eximiriam de sujeitarse à lei generalizante. $\mathrm{O}$ traço da plasticidade sintetiza boa parte da permeabilidade do brasileiro ao estrangeiro e tem duas raízes principais: a tendência à dependência (herdada de uma colonização ao mesmo tempo autoritária e paternalista) e o gosto pela miscigenação (derivada da ausência do orgulho de raça do povo colonizador). Esse traço influenciou profundamente a formação do brasileiro no comportamento extremamente permeável ao estrangeiro, seja este pessoa, produto ou referência. ${ }^{9}$ Por fim, o formalismo, ou seja, a tendência de aceitar e provocar a discrepância entre o formal e o real, entre o dito e o feito, ${ }^{10}$ explica por que a plasticidade brasileira à influência estrangeira não implica que essas influências sejam usadas na forma original.

\section{Contexto atual e importação administrativa no Brasil de hoje}

Como diversos outros países latinoamericanos, só recentemente o Brasil acordou para o mundo exterior, após décadas de isolamento e de políticas protecionistas. Problemas de base nos campos econômico e social, em geral advindos da formação histórica e cultural do País, testemunham a persistência do subdesenvolvimento. Já as pressões econômicas reais, provenientes da inserção do País no mercado internacional, causam uma corrida frenética em toda a economia para recuperar o tempo perdido. $\mathrm{O}$ empresariado local, acostumado a condições de concorrência controlada e operando em um mercado protegido, vê-se despreparado para a concorrência internacional. Enquanto essas pressões econômicas determinam o que deve ser feito - modernização da ges- tão, aumento da produtividade, redução de custos etc. - , o discurso dominante no Brasil, economicamente neoliberal e, do ponto de vista gerencial, permeado pela idéia de validade universal dos conceitos administrativos, indica como deve ser feito: a difusão de "modelos de excelência", que, presumidamente, poderiam ser transplantados dos países desenvolvidos para as nações emergentes. Assim, a maioria das empresas locais acaba importando (ou mimetizando) - em grande quantidade e com pouco critério - modelos de gestão, modas e gurus "modernos".

Nesse contexto, termina-se formando um mercado para a compra, reembalagem e revenda de tecnologia gerencial importada, em especial, de modismos administrativos. Diversos agentes de difusão - ou seja, atores e fatores que agem na filtragem, difusão e sustentação de tecnologia gerencial importada - povoam esse mercado. Um primeiro agente é o próprio Estado: sucessivos governos, de diferentes matizes ideológicas, têm apoiado com leis, incentivos fiscais e políticas setoriais a tendência de importação de práticas empresariais. As instituições de ensino técnico e superior de negócios que foram instaladas no Brasil a partir da década de 50 são um segundo agente de difusão: o ensino e a produção de tecnologia administrativa no Brasil foram moldados com base na importação e difusão maciças de referências, métodos e linguagem estrangeiros, em especial, anglo-saxões. Meios de comunicação especializados em negócios (jornais de grande circulação, livros de gestão, publicações e revistas empresariais) constituem um terceiro agente difusor, ajudando na reprodução e difusão de referências empresariais importadas. Por fim, um quarto agente difusor é formado por categorias profissionais: consultores, analistas de treinamento, conferencistas, professores e outros profissionais atuam como legitimadores e impulsionadores do consumo cada vez mais intenso de tecnologias importadas. ${ }^{11}$ Se adicionarmos aos traços culturais brasileiros, descritos acima, a ação intensiva de alguns desses agentes de difusão de tecnologia administrativa estrangeira, o resultado é uma textura organizacional que bebe - direta ou indiretamente - em fontes estrangeiras, tornando a gestão empresarial um campo essencialmente importado. ${ }^{12}$ 
CONSEQÜÊNCIAS DA IMPORTAÇÃO DE TECNOLOGIA GERENCIAL

Pesquisas conduzidas em empresas brasileiras passando por processos de mudança organizacional ${ }^{13}$ sugerem que a importação de tecnologia gerencial em contextos particulares como o brasileiro pode gerar consequiências que contrariem as expectativas dos adotantes, bem como resultados práticos de difícil previsibilidade. No Brasil, três reações podem ser consideradas típicas: (a) comportamento "para inglês ver"; (b) frustração e negação; ou (c) adaptação criativa. Em nossas pesquisas, observamos que, na verdade, esses três comportamen- tos podem conviver em uma mesma organização ou em um mesmo processo, mas um deles tende a predominar sobre os demais (ver Quadro 2).

Mudança "para inglês ver": esse é o mais típico comportamento organizacional brasileiro perante a importação de conceitos e, na prática, consiste em adotar de forma temporária e/ou parcial a tecnologia em questão para aplacar as pressões de adoção sem, no entanto, realizar mudanças substanciais ou ferir aquilo que se considera intocável no status quo. Esse tipo de comportamento também já foi descrito por outros autores, em especial os neo-institucionalistas. ${ }^{14}$ Quando uma reação assim ocorre, o olhar estrangei-

Quadro 2 - Exemplos de reações brasileiras à importação de tecnologia gerencial

\begin{tabular}{|c|c|c|c|}
\hline & EMPRESA A & EMPRESA B & EMPRESA C \\
\hline $\begin{array}{l}\text { Características da } \\
\text { empresa }\end{array}$ & $\begin{array}{l}\text { Empresa privada } \\
\text { brasileira do setor de } \\
\text { comunicações (mídia } \\
\text { impressa e televisão) }\end{array}$ & $\begin{array}{l}\text { Estatal brasileira do } \\
\text { setor de infra-estrutura }\end{array}$ & $\begin{array}{l}\text { Empresa brasileira de } \\
\text { porte médio do setor } \\
\text { metalúrgico }\end{array}$ \\
\hline $\begin{array}{l}\text { Inovação } \\
\text { implantada }\end{array}$ & $\begin{array}{l}\text { Reengenharia dos } \\
\text { processos } \\
\text { administrativos }\end{array}$ & $\begin{array}{l}\text { Processo abrangente de } \\
\text { "transformação } \\
\text { empresarial" voltado } \\
\text { para o aumento da } \\
\text { competitividade }\end{array}$ & $\begin{array}{l}\text { Revisão do modelo de } \\
\text { gestão de recursos } \\
\text { humanos com foco na } \\
\text { modificação do sistema } \\
\text { de remuneração }\end{array}$ \\
\hline $\begin{array}{l}\text { Traços culturais } \\
\text { relevantes }\end{array}$ & $\begin{array}{l}\text { Ambigüidade e } \\
\text { formalismo }\end{array}$ & Formalismo & $\begin{array}{l}\text { Plasticidade e } \\
\text { "antropofagia" }\end{array}$ \\
\hline $\begin{array}{l}\text { Forma e } \\
\text { características da } \\
\text { adoção }\end{array}$ & $\begin{array}{l}\text { "Só para inglês ver": } \\
\text { Implantação motivada } \\
\text { pela constatação de que } \\
\text { outras empresas do } \\
\text { setor estavam fazendo o } \\
\text { mesmo } \\
\text { Foco em processos } \\
\text { secundários } \\
\text { Abandono do projeto } \\
\text { quando a metodologia } \\
\text { de reengenharia saiu de } \\
\text { moda }\end{array}$ & $\begin{array}{l}\text { Frustração: } \\
\text { O desenvolvimento do } \\
\text { projeto envolveu } \\
\text { consultorias } \\
\text { internacionais e escolha } \\
\text { de "pacotes" } \\
\text { Impedimentos legais a } \\
\text { mudanças na estrutura } \\
\text { da empresa e no } \\
\text { contrato de trabalho } \\
\text { impediam a adoção de } \\
\text { qualquer solução } \\
\text { proposta } \\
\text { Permanece a busca por } \\
\text { novos "pacotes" }\end{array}$ & $\begin{array}{l}\text { Adaptação criativa: } \\
\text { A falta de soluções } \\
\text { disponíveis no mercado } \\
\text { levou ao desenvolvimento } \\
\text { de uma parceria com } \\
\text { uma empresa de } \\
\text { consultoria para o } \\
\text { desenvolvimento de um } \\
\text { sistema próprio } \\
\text { A interação entre os } \\
\text { conceitos trazidos pelos } \\
\text { consultores e as condições } \\
\text { específicas da empresa e } \\
\text { de seus colaboradores } \\
\text { resultou em um modelo } \\
\text { específico de gestão }\end{array}$ \\
\hline
\end{tabular}

13. WOOD, T., CALDAS, M. Importação de tecnologia gerencial no Brasil: o divórcio entre substância e imagem. In: XXI ENANPAD, área de organizações (I), set. 1997, Angra dos Reis.

14. MEYER, J. W., ROWAN, B. Institutional organizations: formal structure as myth and ceremony. American Journal of Sociology, v.83, 1977, p.340-63. 
ro percebe apenas uma pseudo-realidade que parece conformar-se a modelos e referenciais globalizados de gestão. Mas isso é apenas aparência: abaixo dessa superfície - plástica e permeável ao novo - permanece a substância híbrida e diversa, somente parcialmente receptiva a modelos alienígenas. Erroneamente, tem-se a sensação de que a realidade organizacional brasileira esteja povoada por fenômenos gerenciais típicos, idênticos aos padrões internacionais quando, de fato, existe uma realidade distinta, disfarçada "para inglês ver". O comportamento "para inglês ver" é exemplificado pela empresa " $A$ " do Quadro 2.

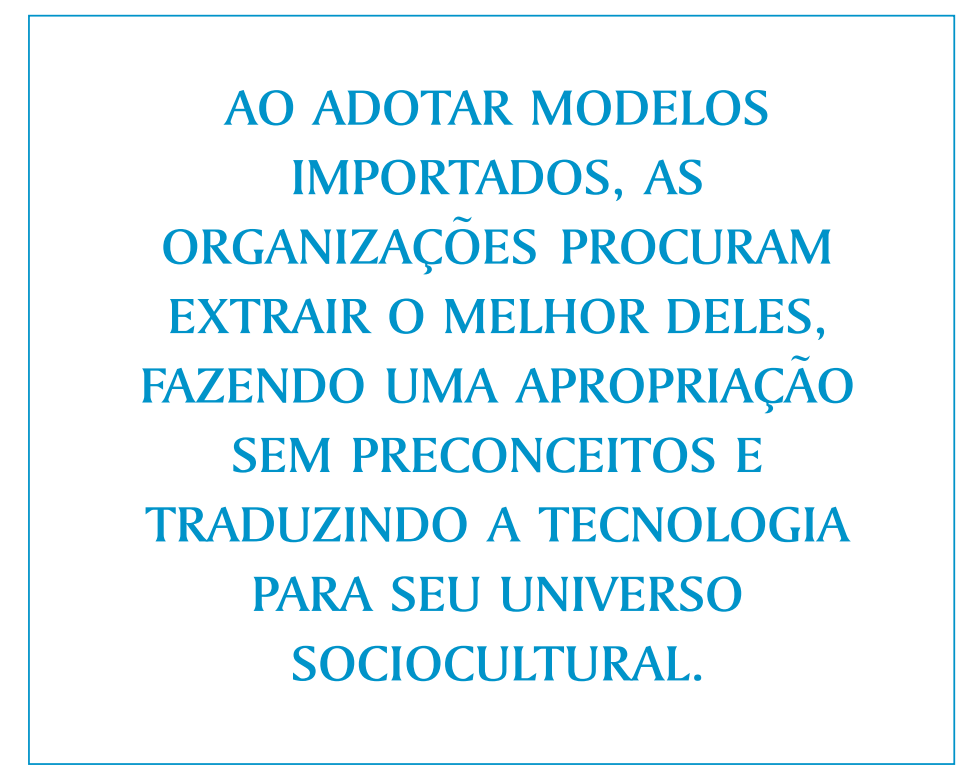

Frustração e negação: um outro tipo de reação ocorre quando a adoção da tecnologia estrangeira não tem como funcionar, e a sua dissimulação "para inglês ver" é insuficiente ou simplesmente impossível. É o caso - exemplificado aqui pela empresa "B" do Quadro 2 - de organizações protegidas por regulamentação governamental ou que se encontram em segmentos cartelizados. Quando expostas à perspectiva de mudanças radicais no cenário competitivo, costumam procurar socorro em grandes empresas de consultoria. Sua expectativa é a de que grandes processos de mudança possam redimilas de sua condição de futuro anacronismo. Implicitamente, entretanto, predomina a vontade de que tudo mude para que fique exatamente como está e que o status quo não seja alterado. Na prática, as mudanças propostas costumam esbarrar em estruturas de poder e condições operacionais não previstas nos pacotes. O resultado é a frustração diante da impossibilidade de realizar sem dor a transformação desejada ou a simples negação da metodologia como inapropriada ao contexto.

Adaptação criativa: por fim, um terceiro tipo de reação é aquela em que a organização não procura fingir que adota uma técnica estrangeira na qual não acredita nem a nega. Nesse caso o que ocorre é uma releitura dos conceitos a partir da realidade local para atender aos objetivos singulares da organização. A adaptação criativa remete ao conceito de "antropofagia organizacional", que será discutido na seção seguinte. Ao adotar modelos importados, organizações como a empresa "C" do Quadro 2 procuram extrair o melhor deles, fazendo uma apropriação sem preconceitos e traduzindo a tecnologia para seu universo sociocultural.

\section{ANTROPOFAGIA ORGANIZACIONAL: UM MÉTODO PARA A ADAPTAÇÃO CRIATIVA}

Entre os três tipos de comportamento ou de reação à adoção de tecnologia gerencial importada em países como o Brasil, certamente a "adaptação criativa" parece ser a mais saudável, apesar de, na prática, ser a mais infreqüente. Nesta seção, desenvolvemos melhor esse tipo de comportamento e recomendamos um método de ação com ele compatível.

O primeiro pressuposto da adaptação criativa é que, se é verdade que a tecnologia gerencial importada de centros desenvolvidos por países emergentes pode não ser diretamente adequada ou aplicável, também é fato que em boa parte dessas referências há conhecimento útil e importante. Ou seja, nem toda essa tecnologia é composta por modelos e técnicas inúteis (embora esse tipo de lixo administrativo não seja difícil de ser encontrado entre os produtos mais populares de importação gerencial). Parte dessa tecnologia é composta por modelos que carregam conhecimento ou referências que de fato podem auxiliar organizações de países em desenvolvimento a competir no mercado internacional. O problema é que, em estado puro, grande parte dessa tecnologia não é apropriada às especificidades locais. $O$ principal 
motivo para essa inadequação é que os pressupostos básicos de muitos desses modelos estrangeiros simplesmente não são reproduzíveis ou transferíveis a contextos distintos do original.

Então, como devem agir organizações em países emergentes, que ao mesmo tempo precisam usufruir do conhecimento útil contido em tecnologia administrativa estrangeira, mas que procuram soluções sustentáveis e apropriadas ao contexto local? Uma solução possível pode ser o que chamamos de "antropofagia organizacional".

Como já lembrado neste artigo, o chamado "antropofagismo literário" criticava a apropriação exagerada e sem sentido de cultura estrangeira, mas, em vez do autismo ou isolacionismo cultural e intelectual, propunha a apropriação sem pudores de idéias e conceitos estrangeiros, argumentando que deveríamos devorá-los após temperá-los com novos significados, tomados de nossos gostos e valores locais.

No campo empresarial, o que é a "antropofagia organizacional”? É a prática despreconceituosa e consciente de garantir a adoção apropriada - ou seja, adequada às especificidades locais - de tecnologia administrativa estrangeira que carregue conhecimentos úteis a países emergentes. Nesse tipo de prática, a organização não adota cegamente, nem tampouco nega indiscriminadamente, modelos vindos de fora. Ela relê e reinterpreta essa tecnologia, procurando entender seus pressupostos fundamentais. Ela a desconstrói com base nas suas próprias especificidades locais. E por fim ela a reconstrói criativamente, "devorando" a essência de seu valor e atendendo de forma apropriada aos seus propósitos singulares e à sua realidade local.

Diferente da retórica gerencialista, para a qual a idéia de adotar "modelos de excelência" estrangeiros "adaptando-os à realidade local" sempre esteve presente no discurso, mas ausente na prática, a proposta de adaptação criativa da "antropofagia organizacional" exige iniciativa e esforço.

\section{Os passos do "método antropofágico": a adaptação criativa na prática}

Um processo de adaptação criativa é necessariamente um trabalho de desconstrução e reconstrução, em que o material bruto é a metodologia original e o projeto é de adoção despreconceituosa apenas do que for apropriado às características locais. Acreditamos que os passos essenciais dessa abordagem seriam:

1. identificar pressupostos;

2. testar a validade e filtrar pressupostos;

3. inserir especificidades locais;

4. reconstruir o modelo;

5. testar e implantar o modelo.

Resumimos a seguir cada um desses passos, utilizando o caso da empresa " $\mathrm{C}$ " como ilustração. A Empresa $C$ é uma metalúrgica brasileira de médio porte. Depois de passar por um processo de reestruturação organizacional, com a revisão do modelo de organização do trabalho, a direção dessa empresa passou a ser pressionada para implementar um novo sistema de gestão de carreiras e salários. Mas, quando a empresa tomou a decisão de investir no sistema, a dificuldade de encontrar ajuda apropriada quase acabou em frustração e desistência. A maioria das empresas de consultoria contatadas queria vender seus pacotes, todos considerados inadequados à configuração estrutural e estratégica única da empresa. A solução veio de um grupo de trabalho interno, que propôs construir um modelo totalmente novo de gestão de carreira e remuneração, baseado nos conceitos de habilidade e competência. Para prover o apoio conceitual necessário, o grupo solicitou a ajuda de consultores externos, especialistas no tema.

A primeira etapa do método proposto, identificação dos pressupostos, é um passo desconstrutivo: o objetivo é identificar e isolar as premissas - raramente declaradas e 
explícitas - nas quais a técnica estrangeira está embasada. Utilizando o modelo de especificidades discutido na primeira seção, é possível identificar os principais elementos de contexto que condicionam os vários elementos da técnica. Assim, é possível isolar os pressupostos institucionais, culturais e organizacionais nos quais cada modelo sob análise é embasado. No caso da Empresa C, três modelos alternativos todos estrangeiros - foram selecionados para análise pelo grupo de trabalho, e cada um foi avaliado por um subgrupo diferente. Para a etapa de identificação de pressupostos, todos usaram critérios idênticos, baseados no modelo de especificidades já mencionado. Nessa etapa, todos os três modelos foram profundamente analisados e desconstruídos. O foco da análise estava centrado em (a) identificar as condições onde, por quem, para quem e com que propósito - em que cada um havia sido criado e (b) explicitar as premissas contidas em cada um desses contextos.

\section{A ORGANIZAÇÃO EM PAÍSES EMERGENTES NÃO DEVE IMPORTAR DE FORMA DIRETA E IRREFLETIDA A TECNOLOGIA ESTRANGEIRA}

O segundo passo, teste de validade e filtragem, envolve analisar os pressupostos isolados para verificar se apresentam consistência razoável com as especificidades do contexto local: caso tal consistência seja improvável ou impossível de ser atingida por adaptação, o modelo é descartado. Esse passo foi vital no caso da Empresa C. Dos três modelos estudados, um apresentava não apenas especificidades culturais incompatíveis com o contexto brasileiro, como também supunha algumas variáveis organizacionais - em especial aquelas relacionadas a estrutura e gestão de processos - que eram irremediavelmente contraditórias à nova configuração recém-implantada. Esse mo- delo foi, então, descartado. Os dois restantes não eram inteiramente compatíveis com as especificidades da Empresa $\mathrm{C}$ e de seu contexto, mas as inadequações eram mais limitadas, sendo filtradas dos dois modelos.

$\mathrm{Na}$ terceira etapa, inserir especificidades locais, procura-se adicionar aspectos e premissas peculiares do contexto local que não existiam no modelo original, em substituição e em adição àqueles filtrados por inadequação no passo anterior. Essa é uma das etapas mais demoradas do processo, pois envolve pesquisa, detalhamento de requisitos e verificação de compatibilidade com os demais elementos originais (inclusive os componentes informatizados) de cada modelo. Do ponto de vista institucional, em ambos os modelos restantes, tiveram de ser acrescentados requisitos legais do ambiente trabalhista brasileiro, bem como a potencialidade de instabilidade econômica e inflacionária, estranha aos modelos originais. Quanto aos elementos culturais, a principal incorporação foi a inclusão de elementos menos formais na metodologia de valoração das competências, o que era essencial à realidade brasileira. Por fim, no âmbito organizacional, o desenho de todo o modelo teve de incorporar competências gerenciais distintas ao modelo original, que foram inseridas para dar sustentação à nova configuração organizacional recentemente adotada.

No passo seguinte, reconstrução do modelo, cada um dos modelos é recomposto conceitual ou logicamente, incorporando tanto os novos requisitos quanto os antigos elementos em um todo coerente. É também nesse momento que uma idéia mais clara da relação custo-benefício de cada adaptação pode ser percebida e repensada e pode ser tomada uma decisão avançada de descarte ou de adoção. Foi o caso dos modelos analisados pela Empresa C. Após todas as adições e revisões de requisitos, o modelo da empresa parceira, favorito de alguns dirigentes da empresa, teve de ser descartado: não apenas algumas edições no modelo tinham-no transformado em um híbrido disforme como o custo previsto da adaptação dos sistemas computadorizados que lhe davam suporte excederia em muito o benefício projetado. Por sua vez, o modelo remanescente - também um híbri- 
do com apenas pequena semelhança com o original - preenchia a maioria dos requisitos essenciais, a um custo suportável.

Por fim, o quinto passo envolve o teste e a implantação do novo modelo. Em caso de incompatibilidade ou dificuldade na implantação, é comum que uma tentativa de readequação ocorra (voltando alguns passos do processo sugerido) antes que se decida por um descarte tardio. Na Empresa C, o tempo total de desenvolvimento do novo sistema foi de quase dois anos. Os custos de adaptação, teste e implantação foram reduzidos pelo interesse de uma empresa de consultoria na comercialização posterior do modelo, que surgia da confluência de necessidades e condicionantes locais com os conceitos mais modernos de carreira e remuneração. Apesar de o projeto ter sido considerado um sucesso, o (longo) tempo para conclusão foi visto internamente como ponto de preocupação, pois originou tensões consideráveis entre operários e empresa.

Hoje, o novo sistema de remuneração e carreira da Empresa $\mathrm{C}$ é considerado um modelo revolucionário no País. E, a despeito das convicções de muitas das pessoas envolvidas no projeto, a empresa orgulha-se de ser um dos pontos de peregrinação de muitas organizações que buscam emular o sistema, desconhecendo sua "estratégia antropofágica" de construção - verdadeira base revolucionária da mudança.

\section{COMENTÁRIOS FINAIS}

O propósito deste artigo foi o de discutir a importação de tecnologia administrativa de países desenvolvidos para contextos socioculturais diferentes dos originais e, em especial, para nações emergentes como o Brasil. Mais especificamente, o objetivo foi o de mostrar por que tal importação ocorre, por que particularidades locais tendem a provocar resultados inesperados nessa importação e, por fim, propor um método de ação para a adoção apropriada de tecnologia de gestão para países emergentes.

A partir da origem histórica, de alguns traços culturais e do contexto econômico contemporâneo do Brasil, construímos um quadro das especificidades dos ambientes empresarial e de trabalho brasileiros. Depois, mostramos alguns dos fatores que levam países como o Brasil a importar em larga escala tecnologia administrativa de países desenvolvidos. Em seguida, contrastamos essa tendência a importar com as especificidades locais para mostrar por que tal importação não funciona em sua forma pura e como o ambiente local acaba reagindo à adoção de tecnologia administrativa estrangeira. Por fim, sugerimos um método para a adaptação criativa e apropriada de tecnologia gerencial importada por empresas em países emergentes, que denominamos "método antropofágico": o que se sugere é que a organização em países emergentes não deve importar de forma direta e irrefletida a tecnologia estrangeira, mas deve, quando for essencial utilizar modelos estrangeiros, selecionar sem preconceitos e de forma criativa o que de melhor tais referenciais estrangeiros podem oferecer.

Acreditamos que os fenômenos aqui analisados não são exclusivos do ambiente brasileiro: seja a tendência à importação ou as reações causadas pela incompatibilidade com especificidades locais ou ainda a propriedade da "adaptação antropofágica". Acreditamos que as causas e o método de ação sugeridos são apropriados à realidade tanto de outras nações latino-americanas - em função da proximidade cultural, social e econômica - como de outros países emergentes. As condições locais do Brasil podem magnificar ou dar tempero particular aos fenômenos e reações estudados, que, porém, não lhe são exclusivos.

Pensamos que o método de ação aqui sugerido pode ser útil tanto para empresas de países emergentes como para empresas de países desenvolvidos operando em países emergentes. Nesse sentido, entender melhor a dinâmica da importação de tecnologia administrativa, bem como formular estratégias para a sua adoção apropriada por empresas locais, pode ser propósito fundamental não só para estudiosos e empresas no Brasil, mas também em países emergentes em geral.

Em um plano ainda mais abrangente, as reflexões propostas por este trabalho podem também ser aplicadas de forma genérica a organizações interessadas em melhor compreender seus sucessos e fracassos na condução de processos de mudança, a partir de uma análise mais crítica da amplitude de aplicação da tecnologia gerencial adotada. 